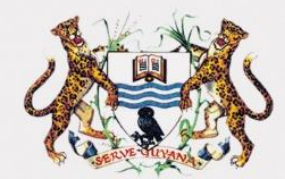

UNIVERSITY of GUYANA
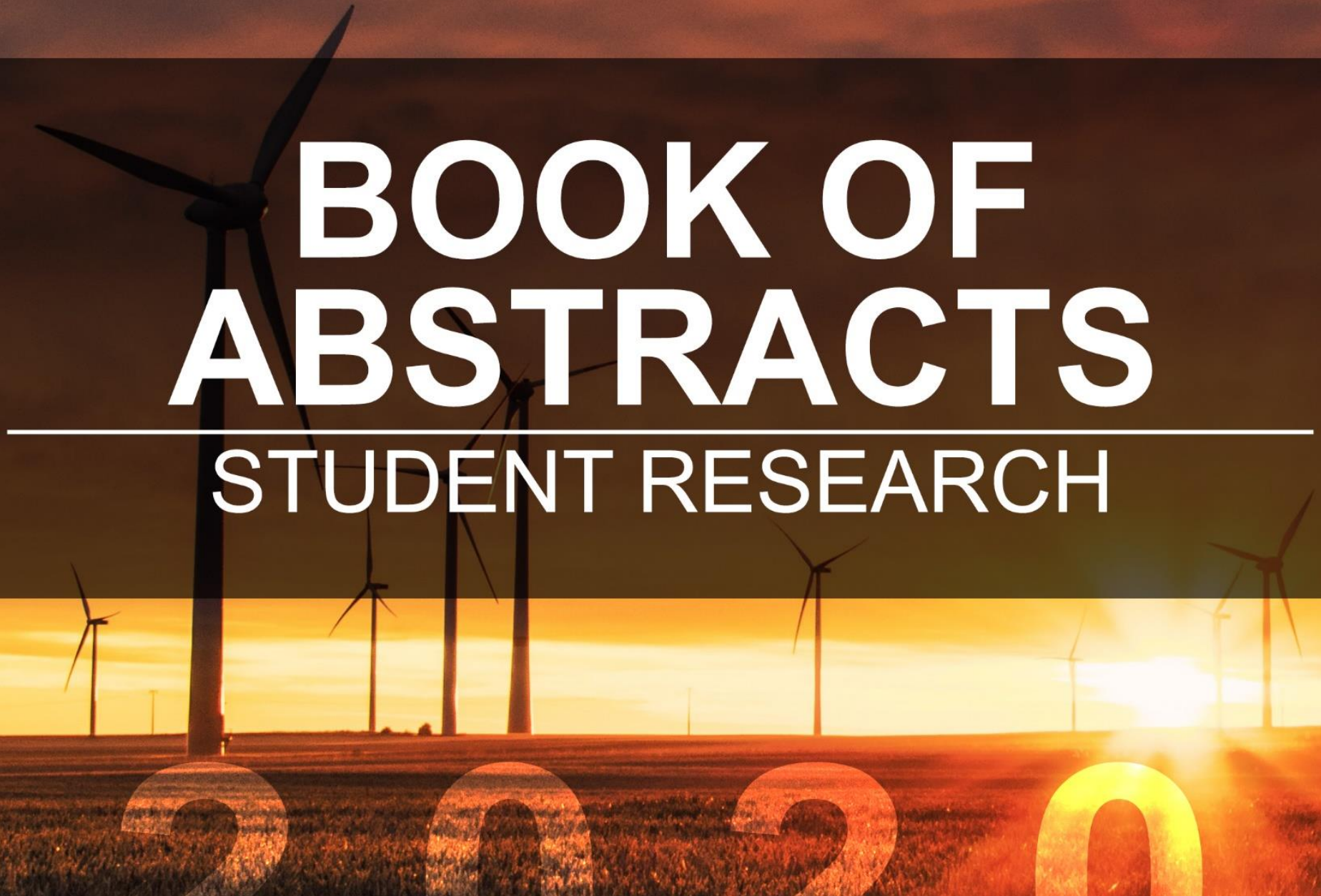

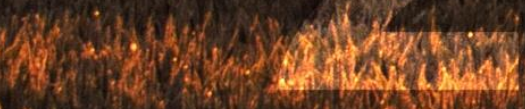




\section{University of Guyana}

\section{BOOK OF ABSTRACTS STUDENT RESEARCH}

\section{0}

Department of Environmental Studies Faculty of Earth and Environmental Sciences
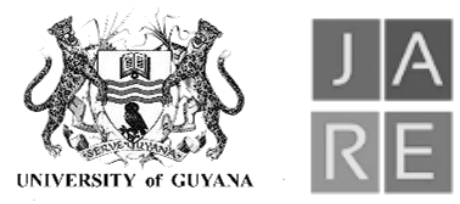


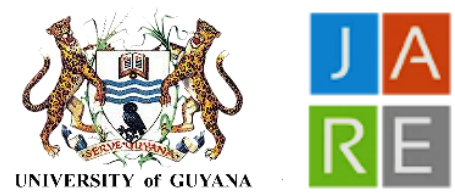

Journal of Academic Research and Essays (JARE)

Faculty of Earth and Environmental Sciences

Leslie P. Cummings Building

University of Guyana - Turkeyen Campus

Turkeyen, Greater Georgetown

Guyana

P.O. Box 10-1110

https://jare.org.gy/

ISSN: 2709-524X

ISSN-L: 2709-524X

DOI: 10.52377/PYHP5589

\section{Editors}

Coretta Remington

Khadija Benn

Shanomae Rose

Associate Editor

Chamique Steele

Typesetting and Layout

Khadija Benn

\section{Cover Design}

Danniebelle Mohabir

\section{(C) 2020 JARE and the Authors}

No article (in part or whole), within this publication can be reproduced without the permission of the (lead) author. 


\section{Acknowledgement}

The Department of Environmental Studies, Faculty of Earth and Environmental Sciences would like to express its sincerest gratitude to those graduates and students who have submitted abstracts, and gave permission for them to be published. The success of this book would not be possible without your willingness, active participation and dedication. We would also like to thank all of the supervisors and resource persons who generously agreed to work with our students and offered their time, patience, and efforts to support them throughout their research.

Special thanks are extended to the Journal of Academic Research and Essays, for providing the platform within which our students, both present and former, can showcase their work.

No one who achieves success does so without acknowledging the help of others. The wise and confident acknowledge this help with gratitude.

— Alfred North Whitehead _ 


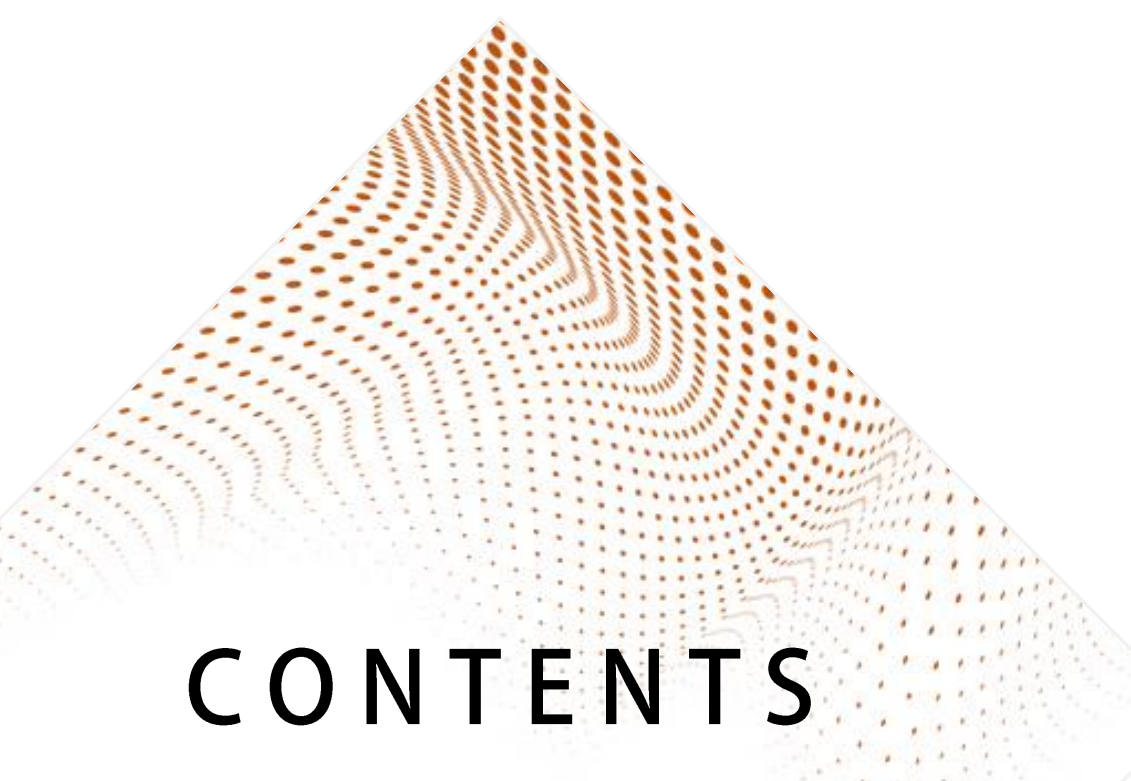


Foreword

8

Air Quality

A Comparative Study of the Concentration of Ambient Particulate Matter of Size 2.5

11

microns in Georgetown

An Investigation of the Indoor Air Quality at Two Nursery Schools

12

An Assessment of Occupational Safety \& Health Hazards, Health Problems, and Safety Practices in the Operational Environment of Petrol Stations

13

Climate Change

An Investigation of the Carbon Emissions and Climate Change Awareness from the Artisanal and Small-Scale Gold Mining Sector in Guyana: The Case of Mahdia

The Effects of Rising Water Temperatures on Poecilia reticulata Native to Guyana

\section{Environmental Audit}

An Environmental Audit of Aracari Resort

Environmental Problems at Government Housing Schemes: The Case of Five-Miles,

Environmental Planning

A Participatory Mapping approach to Environmental Planning for Sustainable Community Development

Ethno-Meteorology

Ethno-Meteorology of Upper Mazaruni: Uncovering Indigenous Knowledge of the

Kapon Akawaio People

\section{Forest Ecosystems}

Palm Community along Environmental Gradients from Wallaba to Swamp Forests at Pakuri

\section{Ground Pollution}

Investigating the Use of Water Hyacinth and Rice Hull Biochars to improve the growth of Vigna unguiculata in Cadmium Contaminated Soils

Soil Characterisation Assessment of the Acacia mangium Plantation at Dakoura, Linden

\section{Human Health}

Batavia Residents' Knowledge and Perception of the Potential Health and

Environmental Risks of an Upstream Cyanide Spill from Gold Mining

Psychosocial Hazards faced by Healthcare Workers at a Public Hospital 
A Study on the Effect of Temperature and Storage Time on the Leaching of Antimony (Sb) from Polyethylene Terephthalate Drinking Water Bottles

An Assessment of Healthcare Workers' exposure to Health Hazards in the Accident 33 and Emergency Unit at Georgetown Public Hospital Corporation

\section{Sustainable Agriculture}

Environmentally Sustainable Management of Water Hyacinth (Eichhornia crassipes) in Guyana

An experiment on the Behavioural, Morphometric, and Histopathological Effects of Paraquat Dichloride on Nile Tilapia Fingerlings

Waste Management

An Investigation into the Advancement of Polyethylene Terephthalate (PET)

Beverage Bottle Recycling in Georgetown

A Pilot Study on the Potential for Household Composting at a Rural Community in Guyana

Assessing the Ability of the Perionyx excavatus to Recycle Different Combinations of Organic Waste

An Assessment of the Medical Waste Management System at a Healthcare Facility

A Comparative Study of Solid Waste Generation and Waste Management Practices in Rural and Urban Households in Guyana

Water Quality

An Examination of Selected Physicochemical Water Quality Parameters of the

Rivers near Kaieteur National Park

An Investigation of the Physical Parameters of Water Quality associated with Mangrove Stands along West Coast Berbice

Application of Geospatial Methods to support Water Quality Assessment in Guyana

Water Resource Management

An Investigation of Water Resource Management in the Beverage Industry

Wildlife Ecology

A Study into the Relationship between the Ité Palm (Mauritia flexuosa) and the Tapir (Tapirus terrestris) at Pakuri 


\section{Foreword}

Research is the mandate of any University and this is no different at the University of Guyana. Research offers policy makers an opportunity to make evidence based decisions that are beneficial for national development. The Department of Environmental Studies is committed to this mandate and hence our programmes have a heavy emphasis on research. We are of the view that students who are able to conduct good research will be assets to employers since they demonstrate a capacity for critical thinking, analysis and synthesis of information, and good written communication skills. These skills are nurtured in all of the courses throughout our programmes and are responsible for the quality of the research conducted by our students.

This collection of abstracts is a demonstration of the quality and diversity of research pursued by our students. The topics cover mainstream as well as innovative research that seek to find answers to challenges facing the nation, and I daresay the world, as we attempt to accomplish the sustainable development goals $(4,6,7,12,13,14$, and 15$)$. The diversity is possible because of the interdisciplinary nature of the content covered in the programmes as we try to reinforce the concept that everything is connected to everything else. The quality is bolstered by working with colleagues in sister faculties on campus and partners off campus who are experts in their respective areas.

Publication of the research completed by our students has been done in isolated instances in the past. However, the Department wishes to improve the dissemination of research completed so that it can indeed inform work being done by others locally, regionally, and internationally as well as the decisions being made at the national level. This is our first volume; we will endeavour to publish the work done annually by our students in the future. It is our hope that the publication of our research will enhance interest in the respective areas and the application of findings will inform national development in Guyana.

Shanomae Rose

Head, Department of Environmental Studies 

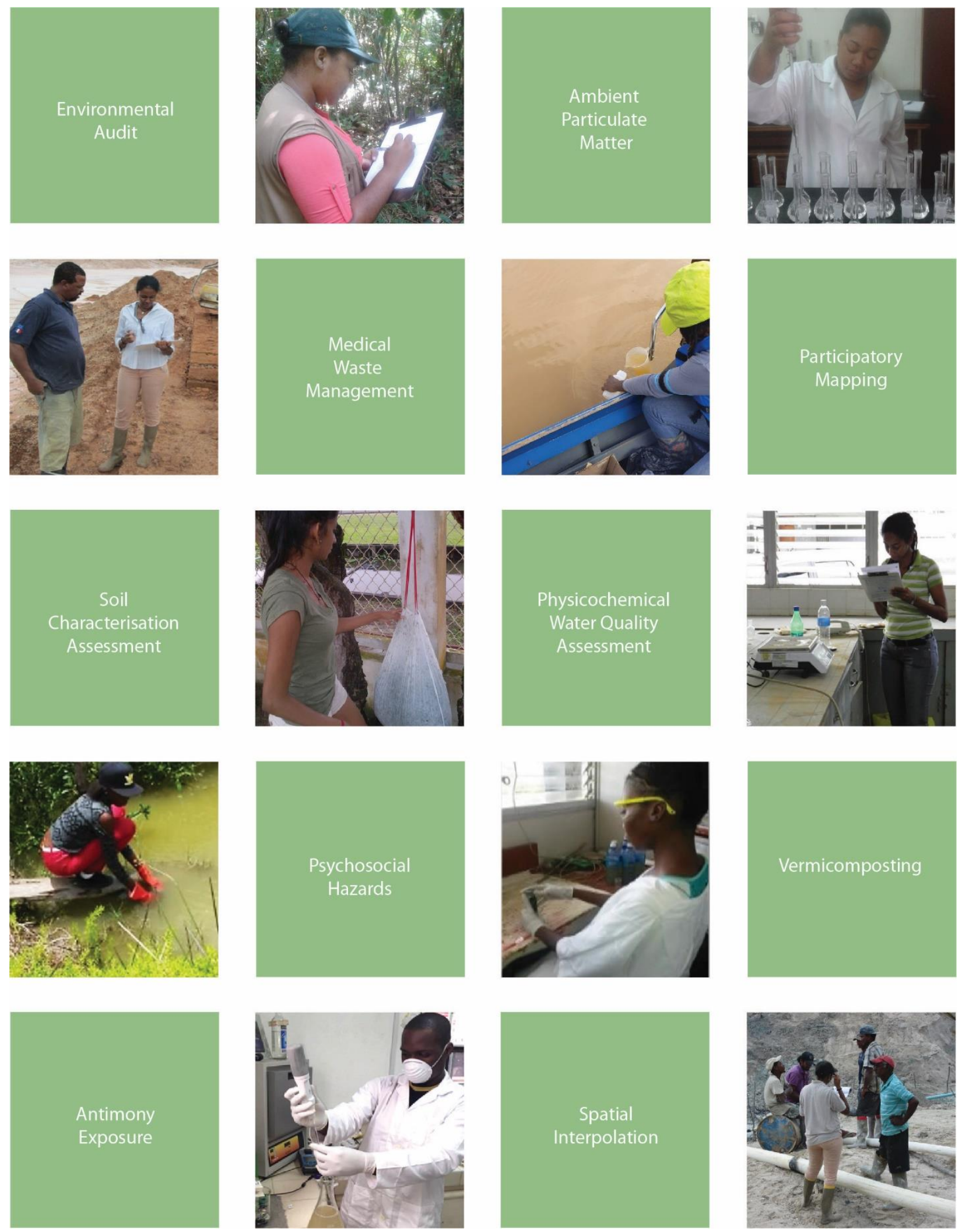

Photographs of student researchers conducting field and lab work, provided courtesy of the authors. 


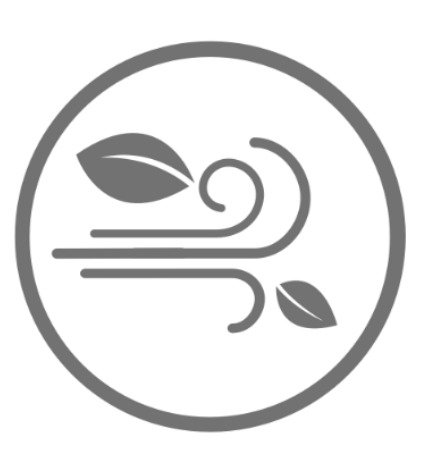

AIR QUALITY

\section{Lead Authors}

Hanover, Kimelly

Harlequin, Rila

Morrison, Micheal 


\title{
A Comparative Study of the Concentration of Ambient Particulate Matter of Size 2.5 microns in Georgetown
}

\author{
${ }^{\star}$ Kimelly Hanover ${ }^{1}$, Denise A. Simmons ${ }^{1}$ and Dawn Roberts-Semple ${ }^{2}$ \\ ${ }^{1}$ Department of Environmental Studies. Faculty of Earth and Environmental Sciences. University of \\ Guyana - Turkeyen Campus. Greater Georgetown, Guyana. ”kimellyhanover@yahoo.com. \\ 2 Department of Earth and Physical Sciences. York College, City University of New York. Jamaica, NY \\ 11451.
}

DOI: $10.52377 / Z F V F 7027$

Air quality is a growing public concern in both developed and developing countries. Over the years, there has been an increase in the number of vehicles on major roadways. Vehicles release particulate matter (PM) into the atmosphere, which adversely affects air quality and, consequently, the health of the population. This study was conducted to measure ambient PM concentrations of size 2.5 microns (PM2.5) along two streets in Georgetown, Guyana; namely Regent Street and Woolford Avenue. Concentrations of ambient PM2.5 were measured using the portable air quality sensor, Airbeam2. Air sampling was conducted during the periods October 2 to 14, 2019 and November 4 to 15, 2019 for two hours daily; at morning, noon, and evening. Mean daily PM2.5 concentrations ranged from 3.87 to $9.78 \mu \mathrm{g} / \mathrm{m}^{3}$ in the vicinity of Regent Street, and from 2.53 to $2.57 \mu \mathrm{g} / \mathrm{m}^{3}$ in the vicinity of Woolford Avenue. A correlation test was used to determine whether a relationship existed between the number of vehicles and PM2.5 levels. The Pearson correlation coefficient test showed a positive correlation of 0.358 between the number of vehicles and PM2.5 concentrations, at a 0.05 significance level. An exposure assessment was also conducted of vendors located along two sections of Regent Street, by calculating their mean daily dose by inhalation. The mean concentration of PM2.5 inhaled by vendors located between Camp and Alexander Streets was $0.00027 \mathrm{mg} /(\mathrm{kg}$-day), while the inhalation level of vendors between Avenue of the Republic and King Streets was $0.00019 \mathrm{mg} /(\mathrm{kg}$-day). Higher levels of PM2.5 were measured along the street with heavier vehicular traffic; concomitantly, this contributed to higher exposure of vendors. This study can be used to extend air quality studies and further examine its impacts on public health.

Keywords: Air quality; PM2.5; public health 


\section{An Investigation of the Indoor Air Quality at Two Nursery Schools}

*Rila Harlequin', Shanomae Rose ${ }^{1}$ and Paul Cheddie ${ }^{2}$

${ }^{1}$ Department of Environmental Studies. Faculty of Earth and Environmental Sciences.

University of Guyana -Turkeyen Campus. Greater Georgetown, Guyana. ㅊilaharlequin@yahoo.com.

2 Department of Medical Technology. Faculty of Health Sciences. University of Guyana - Turkeyen Campus. Greater Georgetown, Guyana.

DOI: $10.52377 /$ HBLA9147

The quality of air in schools is vital because children spend approximately 5-8 hours in school daily. Based on the reviewed literature, most schools recorded poor indoor air quality due to elevated levels of bioaerosols and fine particulate matter (PM2.5) that contributed to severe illnesses in children. This research investigated the indoor air quality at two nursery schools. A quantitative design was employed using the data collection instruments Airbeam2, culture media plates, and observation checklists. The study duration was 4-hours, and revealed that children were exposed to PM2.5 concentrations above and slightly below the World Health Organisation (WHO) 24-hour limit (i.e. $25 \mu \mathrm{g} / \mathrm{m}^{3}$ ). The ANOVA test showed statistically significant differences between the schools' PM2.5 mean concentrations. Moreover, based on the WHO standards, the indoor air quaility at both schools was unacceptable due to markedly high bacterial levels (>500 $\left.\mathrm{CFU} / \mathrm{m}^{3}\right)$. Although fungi levels did not exceed the established WHO limit $\left(<1000 \mathrm{CFU} / \mathrm{m}^{3}\right)$ in most cases, substantial fungi were found within the indoor air of both schools, which can be harmful to children. The dominant bacteria genera were gram-positive cocci and gram-positive bacilli, while the dominant culturable fungal types were Cladosporium herbarum and Chrysonilia sp. School A (53.79\%) and School B (59.09\%) were moderately compliant to standards for a safe classroom environment; however, their compliance percentages fell within the low end of the scale (50-70\%). These results indicated that children are exposed to elevated levels of indoor air pollutants, which may cause health implications such as cardiovascular diseases, respiratory and urinary tract infections.

Keywords: Indoor air quality; health implications, school children 


\title{
An Assessment of Occupational Safety \& Health Hazards, Health Problems, and Safety Practices in the Operational Environment of Petrol Stations
}

\author{
${ }^{*}$ Michael Morrison ${ }^{1}$ and Shanomae Rose ${ }^{1}$ \\ ${ }^{1}$ Department of Environmental Studies. Faculty of Earth and Environmental Sciences. University of \\ Guyana - Turkeyen Campus. Greater Georgetown, Guyana. ${ }^{*}$ michealmorrison30@gmail.com. \\ DOI: $10.52377 / O X D F 6608$
}

Studies have shown that pump attendants are exposed to occupational safety and health hazards, which has health implications. There is also a lack of knowledge amongst pump attendants about key safety measures that can be used to abate these hazards. This study focused on determining BTEX concentrations to which pump attendants are exposed over a forty-hour work week; assessing their knowledge of safety and health hazards, safety practices, and identifying the types of health problems they may have experienced on the job. Using the MiniRAE 3000, BTEX concentrations were measured at six petrol stations in Demerara-Mahaica (Region IV) over five working days. The knowledge and health problems associated with 52 pump attendants were obtained using a structured, interviewer administered questionnaire. An observational checklist was also designed to collect supporting data on daily workplace conditions and practices. At petrol stations $\mathrm{A} 1, \mathrm{~A} 2, \mathrm{~B} 1, \mathrm{~B} 2, \mathrm{C} 1$, and $\mathrm{C} 2$, benzene concentrations were found to be $10.17 \mathrm{ppm}$, 7.84ppm, 10.44ppm, 3.99ppm, 9.65ppm, and 5.96ppm respectively, exceeding the ACGIH's TLVTWA of $0.5 \mathrm{ppm}$. $54 \%$ of pump attendants had poor knowledge of safety and health hazards, whereas $98 \%$ had good knowledge of safety practices. Tiredness, headaches, and lower back pain were reported as the most frequent health problems affecting pump attendants. Binary logistic regression $(p<0.05)$ revealed that gender was a significant predictor of headaches $(p=0.018,95 \% \mathrm{Cl}=0.028-0.718)$ and lower back pain $(\mathrm{p}=0.008,95 \% \mathrm{Cl}=0.011-0.507)$. This study recommends that adequate personal protective equipment and training are needed to safeguard the health and safety of pump attendants.

Keywords: Pump attendants; BTEX concentrations; occupational safety and health 


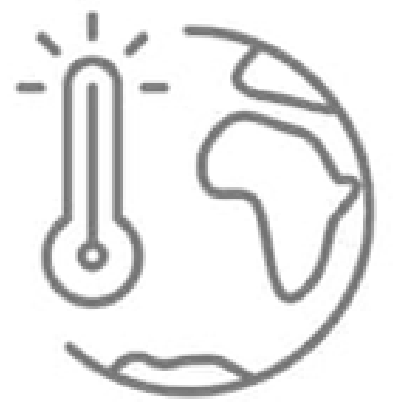

\section{CLIMATE CHANGE}

\section{Lead Author}

McPherson, Soyini A. Jaipaul, Jonathan 


\title{
An Investigation of the Carbon Emissions and Climate Change Awareness from the Artisanal and Small-Scale Gold Mining Sector in Guyana: The Case of Mahdia
}

\author{
*Soyini Ashaki McPherson', Ashley Adams² and David Singh ${ }^{3}$ \\ ${ }^{1}$ Department of Environmental Studies. Faculty of Earth and Environmental Sciences. University of \\ Guyana - Turkeyen Campus. Greater Georgetown, Guyana. *mcphersonsoyini@gmail.com. \\ ${ }^{2}$ Guyana Sugar Corporation Inc. La Bonne Intention, East Coast Demerara, Guyana. \\ ${ }^{3}$ World Wildlife Fund Guianas. Georgetown, Guyana.
}

DOI: $10.52377 / Z L A I 9521$

Mineral extractive industries are becoming increasingly relevant in climate change science and policy. Guyana's economic policy, the Low Carbon Development Strategy, seeks to align sectors of the economy along a low carbon emission trajectory. Although the artisanal and small-scale gold mining (ASGM) sector is economically important, it is a known emissions-intensive sector that contributes to deforestation and direct operational emissions. This study sought to increase understanding of direct operational emissions by investigating carbon emissions associated with fuel combustion in ASGM. Further, the study investigated miners' awareness of carbon emissions and willingness to reduce emissions; thus providing context for policymakers to advance measures aimed at reducing carbon emissions in the ASGM sector. The research methods used were qualitative document analysis, questionnaire-survey, and interviews. It was found that the average carbon dioxide emission per volume of earth moved from a sample of ASGM operations in Mahdia per quarter was $4.69 \times 10^{-6} \mathrm{MtCO}_{2} \mathrm{e} / \mathrm{m}^{3}$. Miners were generally unaware of their carbon footprint and its link to mining, climate change, and the Low Carbon Development Strategy. This knowledge gap was accompanied by negative attitudes. $79 \%$ of miners indicated there is no need to reduce their carbon footprint, and $85 \%$ of miners were unwilling to change their usual practices. Recommendations to advance and integrate the sector within the Low Carbon Development Strategy framework were explored within the themes of: regulation and management; fiscal measures; technology; and education and awareness.

Keywords: Climate change; gold mining 


\title{
The Effects of Rising Water Temperatures on Poecilia reticulata Native to Guyana
}

\author{
*Jonathan D. Jaipaul', Devya Hemraj² and Samantha Providence-Forrester ${ }^{3}$ \\ 1 Department of Environmental Studies. Faculty of Earth and Environmental Studies. Turkeyen Campus. \\ Greater Georgetown, Guyana. *iaipauljonathan@gmail.com. \\ ${ }^{2}$ Centre for the Study of Biological Diversity and Department of Biology. University of Guyana. Turkeyen \\ Campus. Greater Georgetown, Guyana. \\ ${ }^{3}$ Faculty of Agriculture and Forestry. Turkeyen Campus. Greater Georgetown, Guyana.
}

DOI: $10.52377 / D P R L 8943$

The coastal region of Guyana is predicted to experience an increase in annual temperature. Climate change trends indicate that the mean minimum and maximum temperatures will rise above the climatological average. This change in mean temperatures will alter the favourable conditions within coastal ecosystems, which can affect biodiversity. One such at-risk organism is the Guppy (Poecilia reticulata), a species that is particularly sensitive to temperature variations within their habitats. This species was used to observe the potential effects of increasing temperatures on a native species within Guyana's context. This study sought to examine the effects of elevated temperatures on the reproduction and development of Poecilia reticulata by examining the parameters of brood size, sex ratio, and growth performance at sexual maturity. Treatments of $31^{\circ} \mathrm{C}, 32^{\circ} \mathrm{C}$, and a control treatment at room temperature $\left(27^{\circ} \mathrm{C}\right)$, were used to rear adult male and female Poecilia reticulata and subsequent fry after succeeding parturition. The results indicated that brood sizes increased with lower temperatures. Those reared at room temperature produced higher than those reared at $31^{\circ} \mathrm{C}$, while specimens reared at the highest temperature $\left(32^{\circ} \mathrm{C}\right)$ produced no progeny. Mortality was particularly observed for both male and female adult specimens at $32^{\circ} \mathrm{C}$, with females exhibiting morphological aberrations. The sex ratios of progenies differed from a balanced sex ratio (1:1): more females were observed in the control treatment, while more males were observed at $31^{\circ} \mathrm{C}$. However, neither sex ratio nor growth performance (length and weight gain) at $31^{\circ} \mathrm{C}$ was statistically significant ( $\left.p>0.05\right)$. Overall, these findings suggest that elevated temperatures can be harmful to Poecilia reticulata reproduction and development. Rising water temperatures may threaten the stability of the Poecilia reticulata population if climate change trends continue as predicted.

Keywords: Climate change; temperature; Poecilia reticulata 


\section{ENVIRONMENTAL AUDIT}

\section{Lead Authors}

Sawh, Natasha

Wilson, Shania 


\title{
An Environmental Audit of Aracari Resort
}

\author{
${ }^{\star}$ Natasha Sawh ${ }^{1}$, Paulette Bynoe ${ }^{1}$ and Denise A. Simmons ${ }^{1}$ \\ ${ }^{1}$ Department of Environmental Studies. Faculty of Earth and Environmental Sciences. University of \\ Guyana - Turkeyen Campus. Greater Georgetown, Guyana. *natashasawh 247@hotmail.com. \\ DOI: $10.52377 / \mathrm{UGQX9907}$
}

Tourism impacts the economy, the natural and built environment, the immediate population, and even tourists - the very resource needed by the industry to remain viable. Regular assessment of the environmental performance of the industry is necessary to ascertain compliance with national standards and regulations. This is achieved with an environmental audit. To this end, an environmental audit was conducted at the Aracari Resort, almost a decade after it began operations. The Resort's operations should have minimal impact on public health and the environment, as evidenced by good sanitation, safety measure implementation, and adherence to the Public Health Legislation and Occupation Health \& Safety Act. The methodology used included monitoring of water quality and use, noise, and energy; and direct observation of waste and safety management. The results showed that water quality parameters such as $\mathrm{pH}$, temperature, phosphorus and ammonium were in compliance with the national effluent discharge guidelines; however, chlorides, chemical oxygen demand, and total suspended solids were not. Water metre readings revealed an average daily water consumption of $22.5 \mathrm{~m}^{3}$ and an average weekly water consumption of $135 \mathrm{~m}^{3}$. Noise produced from the Resort was in compliance with the daytime limits of $75 \mathrm{~dB}$ based on the national standard, but exceeded residential nighttime limits (from Friday to Sunday) of $60 \mathrm{~dB}$. The average (55.6 kW), maximum (83.85 kW), and minimum $(51.9 \mathrm{~kW})$ power demands across a 7 -day period were obtained from Fluke Monitoring System readings. Solid waste management was observed to be inadequate on days of planned events, with overflowing bins evident on the premises. Safety measures were implemented for food, chemical handling and storage, swimming pool safety, and fire safety, which were observed to be consistent with the standards. The facility's overall performance was satisfactory based on the evaluation criteria, and some environmental practices of Aracari Resort conformed to the Environmental Protection Agency requirements and other established guidelines. Areas identified for improved compliance and enhanced environmental management included the implementation of an environmental policy, regular monitoring of environmental parameters, and staff training on the terms and conditions of the Environmental Permit.

Keywords: Environmental audit; environmental monitoring 


\title{
Environmental Problems at Government Housing Schemes: The Case of Five-Miles, Bartica
}

\author{
*Shania Wilson', Dina Khadija Benn² and Rawle Edinboro \\ ${ }^{1}$ Department of Environmental Studies. Faculty of Earth and Environmental Sciences. University of \\ Guyana - Turkeyen Campus, Greater Georgetown. *wilsonshania23@gmail.com \\ ${ }^{2}$ Department of Geography. Faculty of Earth and Environmental Sciences. University of Guyana - \\ Turkeyen Campus, Greater Georgetown.
}

DOI: $10.52377 / B K K W 9620$

The UN-Habitat recognises housing as a basic human need, and it is a central tenet articulated under Sustainable Development Goal 11: Sustainable Cities and Communities. In Guyana, this need is principally met by the Housing Act of 1996, which mandates the Central Housing and Planning Authority to establish housing schemes countrywide. Housing scheme establishment can be challenged by the physiographic conditions of hinterland regions. In 2010, the Authority proposed housing development at the periphery of Bartica, Cuyuni-Mazaruni (Region VII), which is earmarked as the nation's model green town. After site analysis signaled unsuitable environmental conditions for housing at an initially proposed location, the housing scheme was developed at the Five-Miles Potaro area. However, allocated lots were still affected by environmental problems. To understand the issue, this research examined the established procedures for housing development in Guyana and the environmental issues experienced at Five-Miles Housing Scheme. Data was collected through review of legislative documents, site visits, and interviews. A root cause analysis showed that the contributing factors to these environmental problems appeared to be inherent to the planning and implementation stages of housing scheme development. At Five-Miles Housing Scheme, rapid-onset erosion prompted the relocation of middle-income residents who were allocated lands at the scheme's easterly sections. Several contributing factors were identified, which were grouped as surface factors (lack of drainage infrastructure and a fragmented development process) and root factors (absence of: an environmental mandate within housing legislation, a land use policy, and an environmental impact assessment). These findings indicate that the legal instruments and policies that guide housing development can benefit from consonance with the Environmental Protection Act, which can help to realise environmental and economic goals in the provisioning of sustainable housing across Guyana.

Keywords: Housing scheme development; environmental problems 


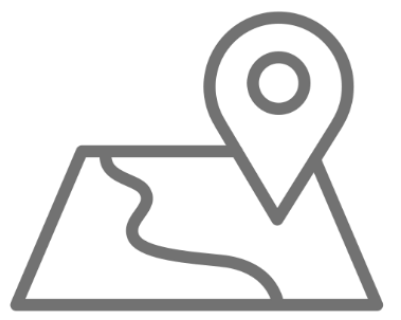

\section{ENVIRONMENTAL PLANNING}

\section{Lead Author}

Higgins, Shamika 


\title{
A Participatory Mapping approach to Environmental Planning for Sustainable Community Development
}

\author{
*Shamika Higgins', Dina Khadija Benn² and Owen Bovell ${ }^{3}$ \\ ${ }^{1}$ Department of Environmental Studies. Faculty of Earth and Environmental Sciences. University of \\ Guyana - Turkeyen Campus. Greater Georgetown, Guyana. *shamika.higgins@gmail.com. \\ ${ }^{2}$ Department of Geography. Faculty of Earth and Environmental Sciences. University of Guyana - \\ Turkeyen Campus. Greater Georgetown, Guyana. \\ ${ }^{3}$ Department of Forestry. Faculty of Agriculture and Forestry. University of Guyana -Turkeyen Campus. \\ Greater Georgetown, Guyana.
}

DOI: $10.52377 / \mathrm{HQDO} 7375$

Indigenous peoples closely rely on land and its resources for their livelihoods and sustenance. The indigenous approach to land use is holistic; satisfying material, social, and cultural needs, with minimal negative impacts to ecosystems. In Guyana, the Low Carbon Development Strategy and the Green State Development Strategy both emphasise community stakeholder collaboration for achieving sustainable development, particularly for indigenous communities. Participatory mapping of customary land uses can empower indigenous peoples by helping them to claim access rights and to facilitate improved systems of land management. This study examined the use of participatory mapping to assess land use and aid community visioning at Pakuri. Landsat 7 images were obtained to facilitate community-based mapping of traditional land uses. Among the prevalent land use activities mapped across Pakuri territory were zones for farming, fishing, and crafting. Information from interviews and focus groups highlighted critical land issues such as resource depletion, soil fertility, and land underutilisation; as well as related social issues such as theft, limited infrastructure, and financing. The study demonstrated the usefulness of participatory mapping as a tool for eliciting rich local knowledge, and produced land use maps that can assist Pakuri with its community development goals.

Keywords: Participatory mapping; community development, indigenous lands 


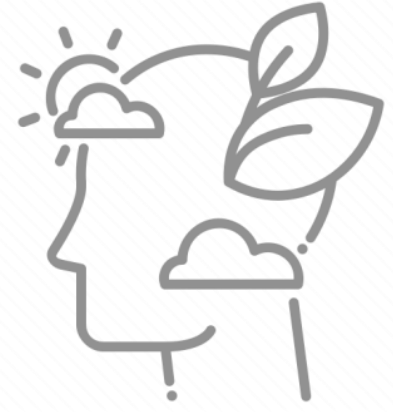

\section{ETHNO-METEOROLOGY}

\section{Lead Author}

Hastings, Romario D. 


\title{
Ethno-Meteorology of Upper Mazaruni: Uncovering Indigenous Knowledge of the Kapon Akawaio People
}

\author{
${ }^{*}$ Romario D. Hastings ${ }^{1}$, Louisa D. Daggers ${ }^{2}$ and Allyson A.M. Stoll ${ }^{1}$ \\ ${ }^{1}$ Department of Environmental Studies. Faculty of Earth and Environmental Sciences. University of \\ Guyana - Turkeyen Campus. Greater Georgetown, Guyana. *romario hastings@yahoo.com. \\ ${ }^{2}$ Faculty of Education and Humanities. University of Guyana - Turkeyen Campus. Greater Georgetown, \\ Guyana.
}

DOI: $10.52377 / C D E K 9254$

Despite ongoing research and interest into indigenous knowledge systems globally, Guyana has yet to draw on the insights of its indigenous peoples. This study describes how the Kapon Akawaio peoples predict and interpret various hydro-meteorological phenomena in Upper Mazaruni; an area with very limited to no access to scientific meteorological information produced by the Guyana Hydro-meteorological Service. The research adopted a mixed methods approach incorporating both quantitative and qualitative methods. Questionnaire survey $(n=171)$, focus group discussions, and key informant interviews were used to collect data from randomly sampled household heads, and purposively sampled elders and community members, respectively. It was found that the Kapon Akawaios do have a repertoire of ethno-meteorological knowledge evidenced through the identification of 92 biophysical and cosmological indicators, which are used to predict rain, sun, water levels, and seasonal onsets. Seventy-seven (77) biological, eight (8) physical, and ten (10) cosmological indicator sets were elicited, of which the majority (85.7\%) relied on plant phenology. The findings of this study augment global research on ethnometeorological knowledge which suffers spatial gaps, and expose the need for further studies in this field across Guyana. They further show that indigenous knowledge systems can provide resources for indigenous peoples in improving livelihoods and adapting to climate variability and change. Importantly, there is need for an information dissemination network to supplement local knowledge in the Upper Mazaruni.

Keywords: Ethno-meteorology; indigenous knowledge; weather forecasting 


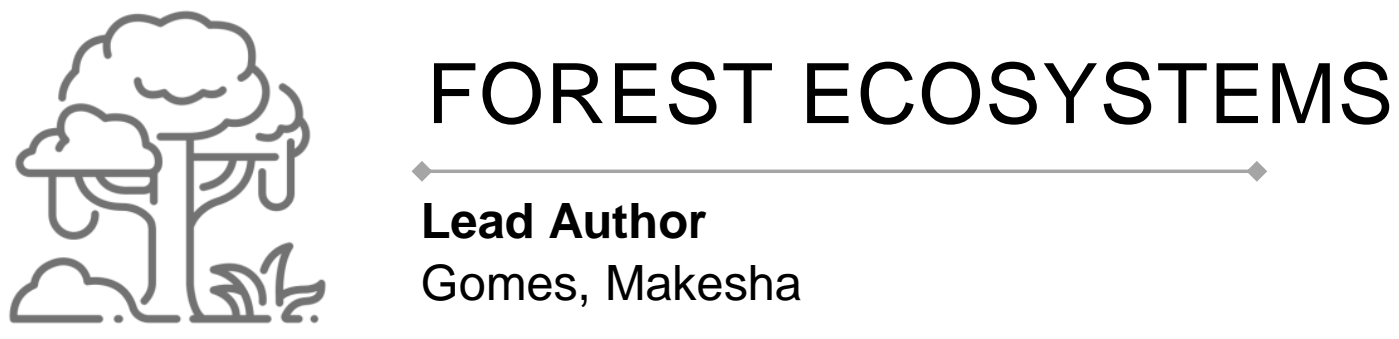




\title{
Palm Community along Environmental Gradients from Wallaba to Swamp Forests at Pakuri
}

\author{
${ }^{*}$ Makesha Gomes ${ }^{1}$, Judith Rosales ${ }^{2}$, Owen Bovell ${ }^{3}$ and Royston Peters ${ }^{3}$ \\ ${ }^{1}$ Department of Environmental Studies. Faculty of Earth and Environmental Sciences. University of \\ Guyana - Turkeyen Campus. Greater Georgetown, Guyana. ”makesha.gomes@gmail.com. \\ ${ }^{2}$ School for Graduate Studies and Research. University of Guyana - Turkeyen Campus. Greater \\ Georgetown, Guyana. \\ ${ }^{3}$ Department of Forestry. Faculty of Agriculture and Forestry. University of Guyana - Turkeyen Campus. \\ Greater Georgetown, Guyana. \\ DOI: $10.52377 /$ ZVGS3968
}

Palms (Arecaceae), characteristic of tropical and sub-tropical regions across the world, are among the oldest monocotyledonous flowering plants, and are important components to the functioning of forest ecosystems. Palm fruits constitute an important food stock for animals, and the animals in turn contribute to their dispersion. Some palm species also offer habitats for many animals. Although palms are widely cultivated in Guyana and play a pivotal role in forest ecosystems, their status is largely unknown. The aim of this research was to document the palm species community along one transect from the Wallaba to the Swamp Forest of Pakuri Lands, which is a predominantly forested area. The specific objectives were to: identify the palm species in a transect from the Wallaba to the Swamp Forest; determine the relative importance of each palm species found based on a calculation using the relative abundance, relative frequency, and relative basal area; analyse whether nitrogen and organic matter in the soils were variables related to the relative importance of the palm species in the communities; and examine the uses of the inventoried species. A $2.5 \mathrm{~km}$ transect was established in the Wallaba forest, with 13 plots of size $20 \mathrm{~m} \times 50 \mathrm{~m}$. Plot centres were $100 \mathrm{~m}$ apart for the first ten, with the last three situated $500 \mathrm{~m}$ apart. The palm species inventoried in the Wallaba Forest were Astrocaryum vulgare, Mauritia flexuosa, Jessenia bataua, Euterpe precatoria, Geonoma baculifera, Maximiliana maripa and two species of Bactris. The most important species was the Jessenia bataua (Turu). Nitrogen and organic carbon appeared to differentiate the three groups of palm communities. A literature analysis revealed that these species are economically and ecological significant; particularly as sources of medicine, craft produce, income, and food. This research serves as a baseline for assessment of Pakuri's palm community status, which can support further analysis for sustainable forest management.

Keywords: Arecaceae; relative abundance; species richness 


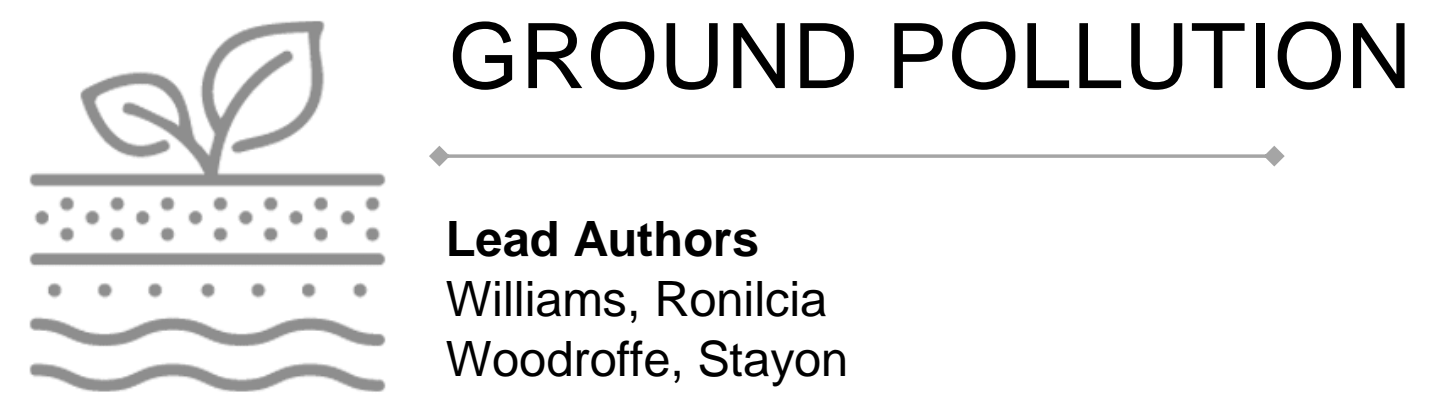




\title{
Investigating the use of Water Hyacinth and Rice Hull Biochars to improve the growth of Vigna unguiculata in Cadmium Contaminated Soils
}

\author{
${ }^{\star}$ Ronilcia Williams ${ }^{1}$, Abdullah Ansari ${ }^{2}$ and Courtney Bullen ${ }^{3}$ \\ ${ }^{1}$ Department of Environmental Studies. Faculty of Earth and Environmental Sciences. University of \\ Guyana - Turkeyen Campus. Greater Georgetown, Guyana. roniwilliams897@gmail.com. \\ ${ }^{2}$ Department of Biology. Faculty of Natural Sciences. University of Guyana - Turkeyen Campus. Greater \\ Georgetown, Guyana. \\ ${ }^{3}$ Department of Agriculture. Faculty of Agriculture and Forestry. University of Guyana - Turkeyen \\ Campus. Greater Georgetown, Guyana. \\ DOI: $10.52377 / Q Y X G 2440$
}

The increase of fossil fuel combustion; application of chemical fertilisers; and advances in metallurgical techniques have prompted the need for sustainable alternatives that remedy heavy metal contamination of soil. Studies show that bio char is an efficient and cost effective material derived from organic biomass; it has the ability to adsorb and remediate heavy metal polluted soils. This study sought to highlight the use of water hyacinth and rice hull derived bio char as a means of improving the growth of Vigna unguiculata grown in cadmium polluted soil. These two forms of feedstock were harvested and subjected to slow pyrolysis using a two-drum kiln. The charred materials were then applied to cadmium polluted soil at two application rates ( $20 \mathrm{t} / \mathrm{ha}$ and $10 \mathrm{t} / \mathrm{ha}$ ). Cadmium soil contamination was simulated by introducing $0.7 \mathrm{mg} / \mathrm{kg}$ of $\mathrm{CdCl}^{2}$ into the soil. The vegetative growth parameters for six treatments were measured and recorded for ten weeks; thereafter, soil was collected and prepared for analysis. The $\mathrm{pH}$ metre and Atomic Absorption Spectroscopy were used to determine soil $\mathrm{pH}$ and cadmium concentration per treatment, and were analysed using ANOVA and pair-wise comparisons. The findings revealed that: cadmium toxicity had a significant effect on the vegetative growth parameters of Vigna unguiculata; rice hulls bio char applied at 20 t/ha was most effective in improving growth in cadmium polluted soil; and water hyacinth and rice hulls bio char were proven to adequately reduce and remove cadmium toxicity.

Keywords: Bio char; cadmium; remediate. 


\title{
Soil Characterisation Assessment of the Acacia mangium Plantation at Dakoura, Linden
}

\author{
*Stayon Woodroffe ${ }^{1}$ and Courtney Bullen ${ }^{2}$ \\ ${ }^{1}$ Department of Environmental Studies. Faculty of Earth and Environmental Sciences. University of \\ Guyana - Turkeyen Campus. Greater Georgetown, Guyana. *stayonwoodroffe98@gmail.com. \\ ${ }^{2}$ Department of Agriculture. Faculty of Agriculture and Forestry. University of Guyana - Turkeyen \\ Campus. Greater Georgetown, Guyana.
}

DOI: $10.52377 /$ SHFT2626

Research suggests that bauxite mining causes extensive damage to soils, alters microbial communities, and affects vegetative health. At the Dakoura mined-out site at Linden, Upper Demerara-Berbice (Region X), reclamation work by the Guyana Geology and Mines Commission aimed to re-establish ecological integrity at this disturbed area. Acacia mangium was selected for site reclamation due to its ability to restore soil fertility and cope in extreme conditions, such as highly acidic soils. This study assessed the effects of Acacia mangium on the physiochemical soil properties at Dakoura, two years after its introduction at the site. Soil samples were retrieved from two locations: within the Acacia mangium plantation, and adjacent zones to the plantation. Top soil was sampled using an auger at $0-15 \mathrm{~cm}$ depth, and the measured parameters were soil $\mathrm{pH}$ and organic matter content. The results indicated that soil $\mathrm{pH}$ and organic matter content increased with the presence of Acacia mangium. Soil pH ranged from 5.1 to 7.5 (within the plantation) and 3.9 to 6.8 (adjacent zones). Organic matter content ranged from 4.19 to 8.36 percent (within the plantation) and 0.36 to 15.1 percent (adjacent zones). It was determined that the maximum readings recorded at the adjacent zones were caused by a waterlogged pond within that particular zone, which slowed anaerobic decomposition of organic material. These findings suggest that Acacia mangium can improve soil quality following intensive mining activity, and should continue to assist the Dakoura Mine reclamation effort.

Keywords: Acacia mangium; soil physiochemical properties; bauxite mining; reclamation 


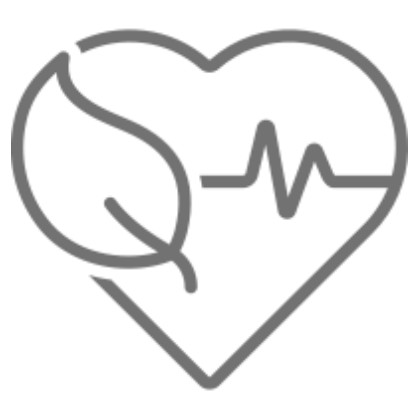

\section{HUMAN HEALTH}

Lead Authors

Bernard, Bonita

Braithwaite, Tricia

Persaud, Ajay A.

Tucker, Merissa 


\title{
Batavia Residents' Knowledge and Perception of the Potential Health and Environmental Risks of an Upstream Cyanide Spill from Gold Mining
}

\author{
*Bonita Bernard ${ }^{1}$, Shanomae Rose ${ }^{1}$ and Cecil Boston ${ }^{2}$ \\ ${ }^{1}$ Department of Environmental Studies. Faculty of Earth and Environmental Sciences. University of \\ Guyana - Turkeyen Campus. Greater Georgetown, Guyana. *b_pbernard2000@yahoo.com. \\ ${ }^{2}$ Faculty of Health Sciences. University of Guyana -Turkeyen Campus. Greater Georgetown, Guyana. \\ DOI: $10.52377 /$ TIIE4213
}

In 1995, a tailings dam at Omai Gold Mining Limited collapsed releasing over 3.2 billion litres of cyanide into the Essequibo River. This incurred both ecological and socio-economic consequences, affecting residents who relied on the river for multiple uses. Communities are often unaware of established mining camps, the dangerous chemicals used in their operations, and the risk they pose downstream. This study aimed to assess community knowledge and perception of the risks associated with an upstream cyanide spill in the Cuyuni River; given that an upstream mining operation was using cyanide in its operations. A cross-sectional survey was conducted in the riverine community of Batavia, Cuyuni-Mazaruni (Region VII), Guyana. A community census was conducted using a structured survey, for which 60 households participated. The results revealed that $41.7 \%(n=25)$ of respondents were not knowledgeable of both the environmental and health risks of cyanide. More females were knowledgeable of environmental risks ( $n=26$, $43.3 \%)$ and health risks $(n=21,35 \%)$ than males $(n=9,15 \%)$ and $(n=14,23.33 \%)$, respectively. Respondents regarded environmental risks $(53.33 \%(n=32))$ and health risks $(60 \%(n=36))$ to be very important. A weak, positive correlation existed between knowledge of health and environmental risks and the perception of these risks among participants $(r=0.29, n=60, p<0.05)$. The inadequate knowledge of risks and awareness in Batavia regarding a cyanide spill renders the community as underprepared to effectively address associated risks. This limited knowledge and awareness increases the potential for stakeholder conflict and inappropriate response in the event of another cyanide spill. These findings can be used to inform regulatory agencies of the community engagement needed to ensure readiness of Batavia and other communities from upstream mining operations that use cyanide.

Keywords: Cyanide spill; knowledge; perception 


\title{
Psychosocial Hazards faced by Healthcare Workers at a Public Hospital
}

\author{
${ }^{*}$ Tricia Braithwaite ${ }^{1}$ and Shanomae Rose ${ }^{1}$ \\ 1 Department of Environmental Studies. Faculty of Earth and Environmental Sciences. University of \\ Guyana - Turkeyen Campus. Greater Georgetown, Guyana. 하iciafia003@gmail.com.
}

DOI: $10.52377 / C N U F 7812$

Public health institutions are an integral part of Guyana's society, within which healthcare workers play a pivotal role. However, research indicates that Guyana's health facilities are under staffed, which can lead to the risk of on-the-job injury. Moreover, other environmental conditions such as the overcrowding of wards, lack of pharmaceuticals and other institutional deficiencies can lead to stress and result in workplace violence. Thus, the objectives of this research were to determine the psychosocial hazards faced by healthcare workers of a public hospital; to ascertain the contributing factors; and to identify the mechanisms that they employ to cope with psychosocial hazards. Using a descriptive, quantitative study design and cross-sectional method, questionnaires were administered to 207 participating healthcare workers of a public hospital. The results showed that bullying and harassment $(34.3 \%)$, violence $(34.8 \%)$, workrelated stress $(70.5 \%)$, lone work $(24.2 \%)$, shift work $(41.5 \%)$, and heavy workload $(71.5 \%)$ are psychosocial hazards faced by the healthcare workers. Analysis of the factors that contributed to psychosocial hazards revealed a positive correlation between lack of experience and workload ( $p$-value $=0.015)$, and being bullied and harassed ( $p$-value=0.009). A positive correlation was also determined between healthcare workers' qualification and high workload ( $p$-value=0.018). Other factors noted were age (25.6\%), gender (19.8\%), attitude (78.3\%), patients' level of comfort $(0.5 \%)$, and years of service $(0.5 \%)$; which increase the likelihood of hazards experienced. The findings also demonstrated that drinking (7\%), eating (26\%), exercising (22\%), listening to music $(5 \%)$, and sleeping (15\%) were the most frequently reported coping mechanisms. This research found that these psychosocial hazards do not usually occur in isolation, and exposure to such hazards may have consequences such as workplace dissatisfaction and staff reduction.

Keywords: Psychosocial hazards; healthcare workers; public hospital 


\title{
A Study on the Effect of Temperature and Storage Time on the Leaching of Antimony (Sb) from Polyethylene Terephthalate Drinking Water Bottles
}

\author{
${ }^{*}$ Ajay Arjoon Persaud ${ }^{1}$, Denise A. Simmons ${ }^{1}$ and Patrick Ketwaru ${ }^{2}$ \\ ${ }^{1}$ Department of Environmental Studies. Faculty of Earth and Environmental Sciences. University of \\ Guyana - Turkeyen Campus. Greater Georgetown, Guyana. *ajay02@yorku.ca. \\ ${ }^{2}$ Department of Chemistry. Faculty of Natural Sciences. University of Guyana - Turkeyen Campus. \\ Greater Georgetown, Guyana.
}

DOI: $10.52377 / L X S U 8411$

We examined the effects of temperature and storage time on the release of antimony from polyethylene terephthalate drinking water bottles to determine whether antimony exposure presented a health risk to consumers. Simulation experiments were based on actual storage conditions recorded at three distributors over an eleven-day period. The highest temperature recorded at the distributor level was $50.8^{\circ} \mathrm{C}$ and a storage time of 7 days. The release of antimony based on temperature and time followed the equation: $\mathrm{C}=\mathrm{C}_{0} \times \mathrm{k} \times \mathrm{e}^{\mathrm{kt}}$. The mean concentrations of antimony released from the experiments were $0.05 \pm 0.01 \mu \mathrm{g} / \mathrm{L}$ at $29^{\circ} \mathrm{C}, 0.12 \pm 0.02 \mu \mathrm{g} / \mathrm{L}$ at $40^{\circ} \mathrm{C}$, and $0.61 \pm 0.02 \mu \mathrm{g} / \mathrm{L}$ at $50^{\circ} \mathrm{C}$. Antimony concentrations increased with storage time, temperature, and with the combined effect of storage time and temperature. However, the Maximum Contaminant Levels of the Caribbean Community $(5 \mu \mathrm{g} / \mathrm{L})$ and the World Health Organisation $(20 \mu \mathrm{g} / \mathrm{L})$ were not violated. The highest chronic daily intake values, which were calculated based on the average daily intake of drinking water (2 litres for adults and 1 litre for children) and average body weight (70 kg for adults, $20 \mathrm{~kg}$ for children), were $28.57 \mathrm{ng} / \mathrm{kg} / \mathrm{d}$ for adults and $50 \mathrm{ng} / \mathrm{kg} / \mathrm{d}$ for children. These values were far below the United States Environmental Protection Agency Reference Dose of $400 \mathrm{ng} / \mathrm{kg} / \mathrm{d}$. Antimony exposure from the leaching of polyethylene terephthalate drinking water bottles investigated in this study does not represent a significant health risk to adults and children.

Keywords: Antimony; polyethylene terephthalate (PET); drinking water 


\section{An Assessment of Healthcare Workers' exposure to Health Hazards in the Accident and Emergency Unit at Georgetown Public Hospital Corporation}

${ }^{*}$ Merissa Tucker ${ }^{1}$ and Tabitha Mallampati ${ }^{2}$

${ }^{1}$ Department of Environmental Studies. Faculty of Earth and Environmental Sciences. University of Guyana - Turkeyen Campus. Greater Georgetown, Guyana. *merissatucker19@gmail.com.

${ }^{2}$ Department of Public Health. Faculty of Health Sciences. University of Guyana -Turkeyen Campus. Greater Georgetown, Guyana.

DOI: $10.52377 / J D Z A 3972$

Georgetown Public Hospital Corporation is Guyana's national referral hospital. Research indicates that one of the main factors affecting the delivery of health care in Guyana is inadequate staff at all levels of the system. This research aimed to assess the health hazard exposure of health care workers at the Accident and Emergency Department. A quantitative cross-sectional study was conducted among fifty doctors, nurses, and technicians. The findings indicated that approximately $50 \%$ of respondents experienced a hazard (85\% experienced non-biological hazards; $78 \%$ experienced biological hazards). Stress (76\%) and sharp injuries (52\%) were reported as the highest non-biological and biological hazards experienced, respectively. A chisquare test indicated no association between working overtime and experiencing a health hazard ( $p$-value=0.853). There was no primary hazard correction measure in place at the Department, and the occupational safety and health conditions were rated as unsatisfactory. Barriers to quality improvement in healthcare were identified as insufficient monitoring, lack of training in occupational safety and health, and poor hazard corrective measures. Factors associated with the health hazards experienced included lack of monitoring, lack of training in occupational safety and health, and poor hazard corrective measures. Interventions should include frequent monitoring by health and safety officers; training in occupational safety and health for healthcare workers; and the implementation of hazard corrective measures according to international standards.

Keywords: Healthcare workers; health hazards; occupational safety and health 


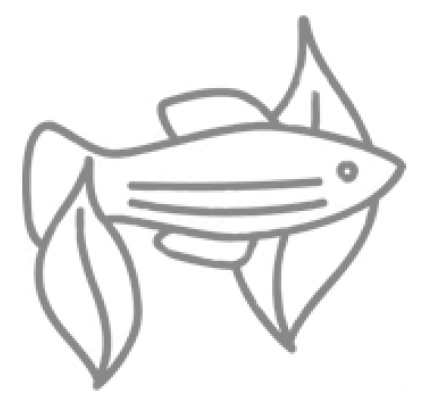

\section{SUSTAINABLE AGRICULTURE}

\section{Lead Authors:}

Cornette, Jonelle

Steele, Chamique C. 


\title{
Environmentally Sustainable Management of Water Hyacinth (Eichhornia crassipes) in Guyana
}

\author{
*Jonelle Cornette ${ }^{1}$, Clairmont Clementson ${ }^{2}$ and David Fredericks ${ }^{2}$ \\ ${ }^{1}$ Department of Environmental Studies. Faculty of Earth and Environmental Sciences. University of Guyana \\ - Turkeyen Campus. Greater Georgetown, Guyana. *cornette jonelle@yahoo.co.uk. \\ ${ }^{2}$ National Agricultural Research and Extension Institute. Mon Repos, East Coast Demerara, Guyana. \\ DOI: $10.52377 /$ UOWL3321
}

The increase of greenhouse gases and chemical fertiliser use due to increasing energy needs have contributed to climate change concerns. This has prompted the need for alternative, environmentally friendly, and renewable sources of energy. The water hyacinth (Eichhornia crassipes) presents a challenge to drainage system management as it is a rapidly growing water weed, and to public health as it provides a breeding area for mosquitoes. Integrated control of water hyacinth can ensure economic and environmental benefits while managing the weed population. This research seeks to highlight an opportunity to derive economic and environmental benefits from water hyacinth, thereby mitigating against its associated environmental issues. This study characterised biochar produced from water hyacinth at three pyrolysis temperatures, then examined its suitability as a soil amendment and its energy and carbon capture potential. Increasing the pyrolysis temperature transformed the biomass matrices into a lighter and porous structure, causing a decrease in density. There was an increase in ash and fixed carbon content, and volatile matter decreased as pyrolysis temperature increased. This indicated that higher concentrations of organic matter from water hyacinth are available for carbon sequestration at higher pyrolytic temperatures. Further, based on the presence of micro-nutrients and high $\mathrm{pH}$, the biochar produced from the samples were suitable as a liming agent and as a soil amendment for vegetables, legumes, and grains, in both open-field and shaded conditions. The water hyacinth biochar is recommended as a fertilisation and soil improvement additive to aid Guyana's agricultural expansion into the Hilly Sand and Clay Region.

Keywords: Water hyacinth; biochar; soil amendment; carbon sequestration 


\title{
An Experiment on the Behavioural, Morphometric, and Histopathological Effects of Paraquat Dichloride on Nile Tilapia Fingerlings
}

\author{
${ }^{*}$ Chamique Chekera Steele ${ }^{1}$, Elford Liverpool ${ }^{2}$ and Lucina Singh ${ }^{3}$ \\ ${ }^{1}$ Department of Environmental Studies. Faculty of Earth and Environmental Sciences. University of Guyana \\ - Turkeyen Campus. Greater Georgetown, Guyana. *shante 96@yahoo.com. \\ ${ }^{2}$ Department of Biology. Faculty of Natural Sciences. University of Guyana -Turkeyen Campus. Greater \\ Georgetown, Guyana. \\ ${ }^{3}$ Office of Climate Change. Ministry of Presidency. Shiv Chanderpaul Drive, Georgetown, Guyana. \\ DOI: $10.52377 / X Q N F 9316$
}

Integrated rice-fish farming has several ecological benefits, which include providing biological control of pests and weeds, and increasing rice yield from the additional nutrients derived from fish faecal matter. Unfortunately, the success of this venture is uncertain due to factors such as limited water availability for irrigation and the contamination of freshwater sources by pesticides like paraquat dichloride, which can cause chronic or acute toxicity of fishes. As a consequence of the latter, behavioural, histopathological and morphometric changes in fishes can occur. This study observed and compared the aforementioned changes in $1 \mathrm{~g}$ and $5 \mathrm{~g}$ nile tilapia (Oreochromis niloticus) fingerlings when exposed to paraquat dichloride. This species was selected since there is an increase in consumer preference for freshwater fishes, and there is high economic potential for nile tilapia. $1 \mathrm{~g}$ and $5 \mathrm{~g}$ nile tilapia fingerlings with average total lengths of $4.172 \pm 0.473 \mathrm{~cm}$ and $6.435 \pm 0.0844 \mathrm{~cm}$, respectively, were exposed to lethal concentrations of $1 \%, 5 \%$, and $24 \%$ paraquat dichloride, along with a control in a static bioassay study. Erratic swimming, hyperactivity, loss of equilibrium, and reduced feeding were among the abnormal behaviours noted for the $1 \mathrm{~g}$ and $5 \mathrm{~g}$ exposed groups. The histopathological changes in the gills, muscles, and intestinal tissues of the exposed fingerlings included necrosis, lesions, and blood clots. The fingerlings were found to have a negative allometric growth pattern. Behavioural and histopathological effects were more severe as the concentration and exposure period increased, with the younger fingerlings more vulnerable to the effects of paraquat dichloride than the $5 \mathrm{~g}$ fingerlings. There were mortalities in all treated groups for both $1 \mathrm{~g}$ and $5 \mathrm{~g}$ fingerlings. The results obtained from this study will add to existing knowledge and can be used to encourage farmers to adopt other pest control measures to reduce contamination of water sources.

Keywords: Integrated rice-fish farming; paraquat dichloride; nile tilapia 


\section{WASTE MANAGEMENT}

\section{Lead Authors}

Bascom, Carlene R.

Dare, Omali

Huntley, Sona

Indarjeet, Madhavi

Jairam, Farah 


\title{
An Investigation into the Advancement of Polyethylene Terephthalate Beverage Bottle Recycling in Georgetown
}

\author{
${ }^{*}$ Carlene R. Bascom 1 , Isidro Ubaldo Espinosa² and Hubert Urlin ${ }^{3}$ \\ ${ }^{1}$ Department of Environmental Studies. Faculty of Earth and Environmental Sciences. University of \\ Guyana - Turkeyen Campus. Greater Georgetown, Guyana. carlene87bascom@gmail.com. \\ ${ }^{2}$ Faculty of Engineering and Technology. University of Guyana - Turkeyen Campus. Greater \\ Georgetown, Guyana. \\ ${ }^{3}$ Construction and Waste Management. Georgetown, Guyana; and \\ Haags Bosch Sanitary Landfill. Eccles, East Bank Demerara, Guyana. \\ DOI: $10.52377 / S H K Y 2058$
}

The present state of improper disposal of waste and the use of traditional methods to deal with waste have resulted in risks to human health and the environment. These risks include air, water, and land pollution. This situation is compounded by the prevalence of polyethylene terephthalate beverage bottles, which are considered stock pollutants. Consequently, there is need for polyethylene terephthalate beverage bottle recycling in the capital city Georgetown. The objective of this study was to justify the need to recycle polyethylene terephthalate; determine advancement opportunities available; and assess the general population's willingness to recycle. A structured survey of 203 households was conducted in Georgetown, along with stakeholder interviews of local polyethylene terephthalate recyclers, beverage company managers, and local waste management experts. The study identified a clear need to recycle polyethylene terephthalate beverage bottles, and revealed a willingness of respondents to participate in recycling. The study also determined that there may be opportunities to advance polyethylene terephthalate recycling if economic incentives and other enabling conditions are made available to consumers.

Keywords: Polyethylene terephthalate (PET) beverage bottle; recycling 


\title{
A Pilot Study on the Potential for Household Composting at a Rural Community in Guyana
}

\author{
${ }^{*}$ Omali Dare${ }^{1}$, Isidro Ubaldo Espinosa ${ }^{2}$, Cecil Boston ${ }^{3}$ and Deon Anderson 4 \\ ${ }^{1}$ Department of Environmental Studies. Faculty of Earth and Environmental Sciences. University of Guyana \\ - Turkeyen Campus. Greater Georgetown, Guyana. omalidare@yahoo.com. \\ ${ }^{2}$ Department of Mechanical Engineering. Faculty of Engineering and Technology. University of Guyana - \\ Turkeyen Campus. Greater Georgetown, Guyana. \\ ${ }^{3}$ Department of Medical Technology. College of Medical Sciences. University of Guyana - Turkeyen \\ Campus. Greater Georgetown, Guyana. \\ ${ }^{4}$ Quality Department. Guyana Water Incorporated. Georgetown, Guyana. \\ DOI: $10.52377 / M F H K 6076$
}

Extensive waste production and population growth have given rise to incremental challenges in the national solid waste management sector. This established a need for sustainable and environmentally-friendly means of waste elimination or reduction. Composting can support this, while adding value to the agricultural sector. A number of composting technologies are available, which are specific to the scale of operation and the available resources. Rotary drum technology is recommended for household composting, while windrows or modular in-vessel containers are more suited to larger operations. Twenty-four (24) questionnaires were administered in the study area using stratified random sampling to collect data on factors that influence the amount and types of waste produced; and household organic waste collected for the purpose of composting. Only $22 \%$ of respondents had very good knowledge of composting, and household organic waste processed into compost returned useful results. It was determined that household size strongly correlated with the mass of waste generated. Chemical analysis of the produced compost indicated the presence of high levels of nitrogen, phosphorous and potassium, which can be beneficial for plant growth once correctly applied. Flyers, seminars, and community engagements were recommended as methods to increase rural community awareness of the benefits of composting.

Keywords: Household composting; solid waste management 


\title{
Assessing the Ability of Perionyx excavatus to Recycle Different Combinations of Organic Waste
}

\author{
${ }^{*}$ Sona Huntley ${ }^{1}$ and Abdullah Ansari ${ }^{2}$ \\ ${ }^{1}$ Department of Environmental Studies. Faculty of Earth and Environmental Sciences. University of Guyana \\ - Turkeyen Campus. Greater Georgetown, Guyana. *sonahuntley@gmail.com. \\ ${ }^{2}$ Department of Biology. Faculty of Natural Sciences. University of Guyana - Turkeyen Campus. Greater \\ Georgetown, Guyana.
}

DOI: $10.52377 /$ SIFL4385

Globally, 1.3 billion tonnes of food produced for human consumption are wasted each year and are usually discarded in landfills where the greenhouse gas, methane, is produced during decomposition. Vermicomposting is a possible organic waste management strategy, which may reduce the amount of food waste disposed in landfills and produce compost, which is a usable end product. This study aimed to evaluate how efficiently the Perionyx excavatus can convert organic waste into quality vermicompost. Three organic waste treatments were used for the process: treatment 1 [fruit waste], treatment 2 [vegetable waste], and treatment 3 [fruit waste + vegetable waste]. A control group without Perionyx excavatus was also established for each treatment. After 38 days, the compost was harvested and weighed, and the daily rate of compost production was calculated. The harvested compost was then subjected to physicochemical analysis to establish the nutrient status. Results indicated that the experimental group had a faster rate of production and generated more compost than the control group, where production was minimal. Treatment 2 produced $515.45 \mathrm{~g}$ of compost, which was the highest among the treatments. The lowest amount of compost was produced by treatment 3 from the control group (184.16g). In terms of nutrient status, higher amounts of nitrogen, phosphorus and potassium were found in the control group; $\mathrm{pH}$ and electrical conductivity were also lower in the experimental group. The results suggest that the Perionyx excavatus has the ability to effectively reduce the volume of organic waste fed into the system and transform it into compost, but its ability to facilitate mineralisation of nutrients may be limited.

Keywords: Perionyx excavatus; compost; organic waste 


\title{
An Assessment of the Medical Waste Management System at a Healthcare Facility
}

\author{
*Madhavi Indarjeet \\ Department of Environmental Sciences. Faculty of Earth and Environmental Sciences. University of \\ Guyana - Turkeyen Campus. Greater Georgetown, Guyana. *anupa1496@gmail.com.
}

DOI: $10.52377 / O J A Z 6369$

Healthcare facilities are among the complex institutions that generate a broad range of hazardous waste, medical infectious waste, during the course of healthcare activities. The medical infectious waste generated are of great importance due to its potential environmental hazards and public health risks. As such, it is imperative that healthcare facilities employ an appropriate system of medical waste management to eliminate the threat of these hazards and risks. Hazardous waste is a small portion of healthcare waste, but the absence of appropriate waste segregation practices often causes hazardous waste to contaminate general (non-hazardous) waste through a process called cross contamination; which results in the entire bulk of waste becoming potentially hazardous. A cross sectional study was employed using questionnaires, interviews, and an observational checklist, to verify whether the current method of waste management at a selected healthcare facility adhered to guidelines provided by the Guyana Environmental Protection Agency. Data were analysed through frequencies and descriptive analyses, then compared with the standard. The results revealed that the current waste management practices at the healthcare facility were unsatisfactory. Healthcare workers displayed limited adherence to standards in the handling of medical waste. These results were due to factors such as limited resources, low levels of training and knowledge, negligence, and poor waste segregation practices. Periodic training, development of a healthcare waste management plan, and audits are recommended to ensure proper handling of medical waste from point of origin to disposal.

Keywords: Medical infectious waste; cross contamination; environmental hazards; health risks 


\section{A Comparative Study of Solid Waste Generation and Waste Management Practices in Rural and Urban Households in Guyana}

*Farah Jairam ${ }^{1}$ and Phillip DaSilva²

${ }^{1}$ Department of Environmental Studies. Faculty of Earth and Environmental Sciences. University of Guyana - Turkeyen Campus. Greater Georgetown, Guyana. *farah.jairam94@gmail.com.

${ }^{2}$ Division of Natural Sciences. Faculty of Natural Sciences. University of Guyana - Berbice Campus. Tain, Corentyne, Berbice, Guyana.

DOI: $10.52377 /$ EENR6350

As the global population increases, consumption behaviour has resulted in the generation of excessive solid waste. Appropriate solid waste management practices are not yet available in many developing countries like Guyana. This study compared solid waste and waste management practices of urban and rural households. The overall objective of this study was to identify and analyse household solid waste categories, and explore the potential impacts of various factors that contribute to waste generation. The study employed a survey method approach using questionnaires and waste generation data sheets. Fifty-two households participated in the survey, comprising rural households in Strathspey and urban households in Bel-Air. The questionnaire focused on socioeconomic factors such as income, household size, and consumption behaviour; as well as current waste management practices, knowledge and awareness, attitudes to solid waste management. The data were analysed using descriptive statistics and Pearson correlation. The results revealed that household solid waste was positively correlated with population size and income. Consumption behaviours and active waste management practices also varied. Rural households produced $375 \mathrm{~kg}$ of solid waste per month, in comparison to $1,365 \mathrm{~kg}$ from urban households. Rural household waste was reused, composted, and burned, while urban household waste was deposited at landfills. Although respondents from both rural and urban households were knowledgeable and aware of solid waste and waste management practices, more members of rural households indicated a willingness to adopt appropriate management practices. A key recommendation emerging from this study is that policies and public awareness and education campaigns should be tailored to address the solid waste management needs of rural and urban areas.

Keywords: Household solid waste; solid waste generation; solid waste management 


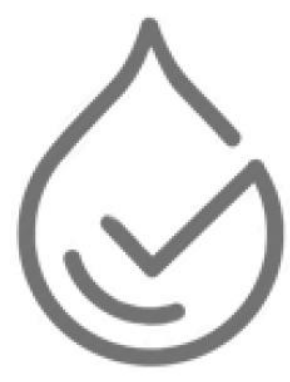

\section{WATER QUALITY}

Lead Authors

Davis, Benita

Mangal, Raveena

Percival, Annthea 


\title{
An Examination of Selected Physicochemical Water Quality Parameters of the Rivers near Kaieteur National Park
}

\author{
"Benita Davis', Temitope D. Timothy Oyedotun² and Denise A. Simmons ${ }^{1}$ \\ ${ }^{1}$ Department of Environmental Studies. Faculty of Earth and Environmental Sciences. University of \\ Guyana - Turkeyen Campus. Greater Georgetown, Guyana. *beni 1995@hotmail.com. \\ ${ }^{2}$ Department of Geography. Faculty of Earth and Environmental Sciences. University of Guyana - \\ Turkeyen Campus. Greater Georgetown, Guyana.
}

DOI: $10.52377 /$ SEJM1908

Studies have indicated that gold mining operations increased within the vicinity of Kaieteur National Park, yet its impacts on freshwater systems could not have been assessed due to an absence of baseline data for water and sediment quality in the area. This study examined the total mercury and non-metallic physiochemical water quality parameters at four sampling sites: Echerak River, Muri-Muri River, Potaro River before Kaieteur Falls, and Potaro River after Kaieteur Falls. The physicochemical parameters $(\mathrm{pH}$, turbidity, total dissolved solids, electrical conductivity and water temperature) were measured in-situ for both sub-surface and depth samples near the sediment. The mercury concentration in sediment and water sampled from Echerak and Potaro (after Kaieteur Falls) rivers were determined during the laboratory analyses. One-way ANOVA, Pearson product moment correlation, and t-test were employed to comparatively analyse the data from the sample sites. The turbidity range $(0.64-42.30 \mathrm{NTU})$ for all the samples was above the World Health Organisation (WHO) guidelines for healthy drinking water, except at Muri-Muri. However, the other physicochemical parameters of the river system were below the WHO guidelines: mean $\mathrm{pH}(3.4-7.7)$, total dissolved solids $(0.00-12.64 \mathrm{mg} / \mathrm{L})$, and conductivity $(0.00-25.20 \mu \mathrm{S} / \mathrm{cm})$. Mercury concentrations in water and sediment samples from Echerak River $(0.082 \mu \mathrm{g} / \mathrm{L} \& 0.021 \mathrm{mg} / \mathrm{kg}$ ) were higher than that of Potaro River (after Kaieteur Falls) $(0.065 \mu \mathrm{g} / \mathrm{L} \& 0.008 \mathrm{mg} / \mathrm{kg})$. At both areas, total mercury in water and sediments were below the guidelines set by WHO $(0.6 \mu \mathrm{g} / \mathrm{L})$; thus are safe for humans and aquatic life. These results can serve as the baseline for physicochemical and mercury evaluation of the area. To extend knowledge on the rivers near this important landmark, an investigation can be conducted on the impacts of the physiochemical parameters and mercury concentrations on the fish population.

Keywords: Kaieteur National Park; total mercury; river 


\section{An Investigation of the Physical Parameters of Water Quality associated with Mangrove Stands along West Coast Berbice}

${ }^{*}$ Raveena Mangal

Department of Environmental Studies. Faculty of Earth and Environmental Sciences. University of Guyana - Turkeyen Campus. Greater Georgetown, Guyana. ㅆmangal.raveena@gmail.com.

DOI: $10.52377 /$ KLVK5595

Both physical and chemical properties are known to affect the development, growth, and productivity of mangroves. There are seventy-three known mangrove species and hybrids worldwide, and considerable variability exists among species with respect to how they survive in different conditions. Mangroves are well known for their ability to withstand high saline conditions and survive in areas with low water quality. Studies have been conducted in some tropical and sub-tropical countries where mangroves are found. However, a study on how specific water quality parameters affect coastal mangrove stands is needed for Guyana. This study assessed the physical water quality parameters $\mathrm{pH}$, dissolved oxygen, turbidity, and temperature to determine their association with mangroves stand classifications along the West Coast of Berbice. Samples were obtained from pools of water within mangrove stands, and at locations in the central discharge façade canal (which is fed by the coastal rice lands and community lands) along which the mangrove stands are found, near the canal mouth. The stands were classified according to whether mangroves were old, new, or receding, after which water quality was measured to determine whether a difference may have occurred due to the presence of particular stands. It was found that the parameters measured were affected by the mangrove stands, but were not necessarily affecting them. The waters servicing the mangrove forests of the West Coast of Berbice did not possess concentrations high or low enough to either have a positive or negative impact on the mangroves. Water quality in mangrove stands is an important issue that should not be overlooked, and this preliminary study can be extended to further investigate the relationship between water quality and mangrove stands.

Keywords: Water quality; mangrove stands; physical parameters 


\title{
Application of Geospatial Methods to support Water Quality Assessment in Guyana
}

\author{
${ }^{\star}$ Annthea Percival ${ }^{1}$, Dina Khadija Benn², Denise A. Simmons ${ }^{1}$ \\ ${ }^{1}$ Department of Environmental Studies. Faculty of Earth and Environmental Sciences. University of Guyana \\ - Turkeyen Campus. Greater Georgetown, Guyana. *annthea.perci@gmail.com. \\ ${ }^{2}$ Department of Geography. Faculty of Earth and Environmental Sciences. University of Guyana - Turkeyen \\ Campus. Greater Georgetown, Guyana.
}

DOI: $10.52377 / D G P K 5456$

Water quality degradation from anthropogenic activities is a critical issue requiring close monitoring and management. The Cuyuni and Mazaruni Rivers; major tributaries of the Essequibo River system in Guyana, feature gold and diamond mining that contribute to elevated levels of sediment loading. These excess sediments could endanger riverine ecosystems and indigenous communities. Water quality monitoring at these sites typically involves purposive in situ sampling and lab analyses, but this procedure can limit more comprehensive analysis. This research examined the usefulness of spatial interpolation for modelling distributions of surface water quality parameters. Twenty-nine river samples were retrieved through stratified sampling along twentytwo (22) kilometres of connected riverine area. Regularly-spaced transects were positioned at four locations: the lower Cuyuni River, the lower Mazaruni River, the Cuyuni-Mazaruni confluence, and the discharge point into the Essequibo River. Samples were tested for turbidity and total suspended sediments using the turbidity meter and filter paper method, respectively. Two spatial interpolation techniques (Inverse Distance Weighted and Ordinary Kriging) were selected to spatially model the samples, and Ordinary Kriging was found to be more accurate for modelling spatial distribution of the surface water quality parameters. Mapping the distribution of turbidity and total suspended sediments using an appropriate sampling procedure helped to identify problematic sediment accumulation zones and link them to nearby unregulated dredging activities. The study demonstrated that incorporating geospatial modelling techniques into water quality monitoring procedures can enable an improved response to unmitigated mining and water quality degradation issues, which can help safeguard communities and riverine ecosystem health.

Keywords: Surface water quality; geospatial methods; spatial interpolation 


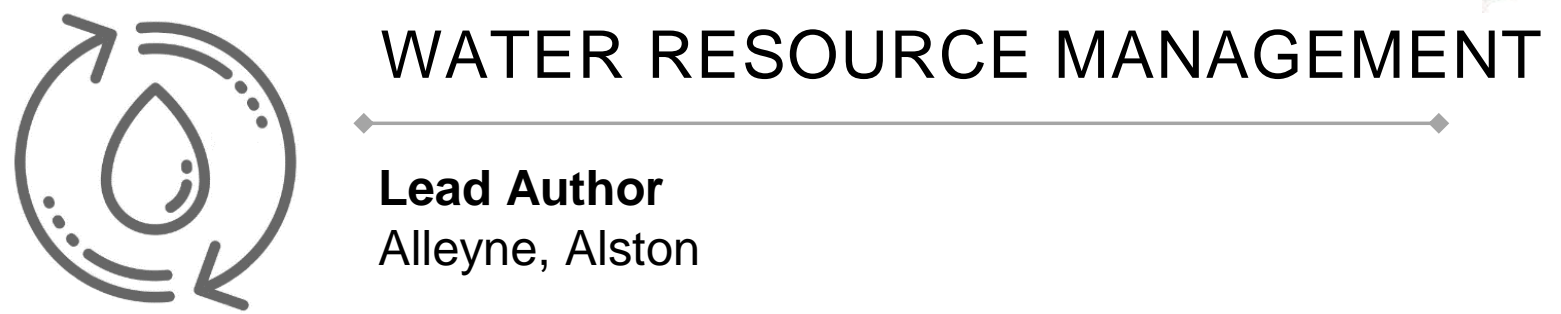




\title{
An Investigation of Water Resource Management in the Beverage Industry
}

\author{
*Alston Alleyne ${ }^{1}$ and Chamique Chekera Steele ${ }^{1}$ \\ ${ }^{1}$ Department of Environmental Studies. Faculty of Earth and Environmental Sciences. University of Guyana \\ $-$ \\ Turkeyen Campus. Greater Georgetown, Guyana. “alstonalleyne@gmail.com. \\ DOI: $10.52377 / D S B N 4892$
}

According to studies, industrial water use comprises production processes, auxiliary processes, kitchen use, and outdoor use. Reducing industrial water use is dependent on the implementation of administrative, engineering, mechanical, and human controls. The objectives of this research were to assess the water use of a Soft Drink Plant; determine the water use ratio for a two-year period; and determine the plant's compliance with local and international regulations for wastewater discharge. We also determined the level of success of implementing a water minimisation plan, whether there was an improvement in the Water Use Ratio, and the compliance of the industry with local and international discharge regulations. The sequential transformative strategy was used to collect and analyse data so as to ascertain water usage and disposal, and a semi-structured interview was conducted to validate the non-existence of heavy metals in the wastewater discharged from the soft drink plant. The Banks DIH Water Minimisation Plan 20132016 achieved a high level of success overall, with $74.42 \%$ of the activities implemented by the assigned completion dates. However, three of the five measures implemented recorded low levels of success. Paired sample t-tests revealed statistically significant differences in the water use ratio obtained for the periods 2013-2014, 2014-2015, and 2013-2015, although the differences were relatively small $(t(d f)=2.242, p=0.047 ; t(d f)=2.592, p=0.025$; and $t(d f)=6.250, p=0.000)$ for the respective periods. Six of the eleven tested parameters were statistically different when compared to the Coca-Cola Operating Requirements and Environmental Protection Agency standards, indicating a high variation in effluent discharge.

Keywords: Water use; effluent; compliance 


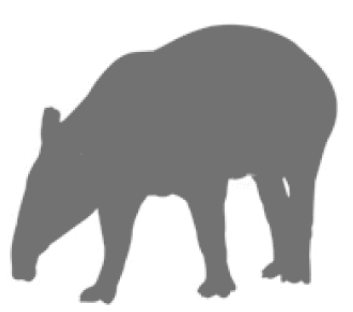

WILDLIFE ECOLOGY
$\begin{aligned} & \text { Lead Author } \\ & \text { Singh, Lakeram }\end{aligned}$ 


\title{
A Study on the Relationship between the Ité Palm (Mauritia flexuosa) and the Tapir (Tapirus terrestris) at Pakuri
}

\author{
"Lakeram Singh ${ }^{1}$, Seon Hamer ${ }^{1}$ and Elford Liverpool ${ }^{2}$ \\ ${ }^{1}$ Department of Environmental Studies. Faculty of Earth and Environmental Sciences. University of \\ Guyana - \\ Turkeyen Campus. Greater Georgetown, Guyana. *indarsingh2011@gmail.com. \\ 2 Department of Biology. Faculty of Natural Sciences. University of Guyana-Turkeyen Campus. Greater \\ Georgetown, Guyana.
}

DOI: $10.52377 /$ NSPD1786

Tropical rainforests are the most biologically diverse terrestrial biomes. As humans increase consumption of forest resources, forests are increasingly hampered from optimally carrying out their ecological functions. The Ité palm is referred to as the tree of life because it provides many materials for the existence of indigenous peoples and animals. Unsustainable harvesting of its fruit, leaves, and other by-products, coupled with its destruction during large scale logging, may have an effect on wildlife that depend on it for survival. The tapir has been observed feeding on this species and is one of the large ungulates that roam the forests. This research sought to determine if there is a distinct and measurable relationship between the tapir and the Ité palm as a main food source. The study was carried out in the Amerindian reservation of Pakuri, mainly along the banks of the Mahaica River. Wildlife camera traps were positioned at areas with fruiting Ité palms, and areas without Ité palms but included other plant species that comprise the tapir diet. However, a relationship could not be established due to unpredictable rainfall and the subsequent flooding of the Ité reefs during the course of this research. Given the value of the lté palm to the community, it is recommended that this research topic be further explored, as well as related studies on the sustainable use of the palm.

Keywords: Habitat destruction; wildlife food sources; wildlife displacement 


\section{Author Index}

Alleyne, Alston; Steele, Chamique C.

An Investigation of Water Resource Management in the Beverage Industry, pp 48

Bascom, Carlene R.; Espinosa, Isidro U.; Urlin, Hubert

An Investigation into the Advancement of Polyethylene Terephthalate Beverage Bottle

Recycling in Georgetown, pp 38

Bernard, Bonita; Rose, Shanomae; Boston, Cecil

Batavia Residents' Knowledge and Perception of the Potential Health and Environmental

Risks of an Upstream Cyanide Spill from Gold Mining, pp 30

Braithwaite, Tricia; Rose, Shanomae

Psychosocial Hazards faced by Healthcare Workers at a Public Hospital, pp 31

Cornette, Jonelle; Clementson, Clairmont; Fredricks, David

Environmentally Sustainable Management of Water Hyacinth (Eichhornia crassipes) in

Guyana, pp 35

Dare, Omali; Espinosa, Isidro U.; Boston, Cecil; Anderson, Deon

A Pilot Study on the Potential for Household Composting at a Rural Community in

Guyana, pp 39

Davis, Benita; Oyedotun, Temitope D.T.; Simmons, Denise A.

An Examination of Selected Physicochemical Water Quality Parameters of the Rivers near Kaieteur National Park, pp 44

Gomes, Makesha; Rosales, Judith; Bovell, Owen; Peters, Royston

Palm Community along Environmental Gradients from Wallaba to Swamp Forests at

Pakuri, pp 25

Hanover, Kimelly; Simmons, Denise A.; Roberts-Semple, Dawn

A Comparative Study of the Concentration of Ambient Particulate Matter of Size 2.5

microns in Georgetown, pp 11

Harlequin, Rila; Rose, Shanomae; Cheddie, Paul

An Investigation of the Indoor Air Quality at Two Nursery Schools, pp 12

Hastings, Romario D.; Daggers, Louisa D.; Stoll, Allyson A.M.

Ethno-Meteorology of Upper Mazaruni: Uncovering Indigenous Knowledge of the Kapon Akawaio People, pp 23

Higgins, Shamika; Benn, Dina K.; Bovell, Owen

A Participatory Mapping approach to Environmental Planning for Sustainable Community Development, pp 21

Huntley, Sona; Ansari, Abdullah

Assessing the Ability of Perionyx excavatus to Recycle Different Combinations of

Organic Waste, pp 40

Indarjeet, Madhavi

An Assessment of the Medical Waste Management System at a Healthcare Facility, pp 41

Jaipaul, Jonathan; Hemraj, Devya; Providence-Forrester, Samantha

The Effects of Rising Water Temperatures on Poecilia reticulata Native to Guyana, pp 16 
Jairam, Farah; DaSilva, Phillip

A Comparative Study of Solid Waste Generation and Waste Management Practices in

Rural and Urban Households in Guyana, pp 42

Mangal, Raveena

An Investigation of the Physical Parameters of Water Quality associated with Mangrove Stands along West Coast Berbice, pp 45

McPherson, Soyini A.; Adams, Ashley; Singh, David

An Investigation of the Carbon Emissions and Climate Change Awareness from the

Artisanal and Small-Scale Gold Mining Sector in Guyana: The Case of Mahdia, pp 15

Morrison, Micheal; Rose, Shanomae

An Assessment of Occupational Safety \& Health Hazards, Health Problems, and Safety

Practices in the Operational Environment of Petrol Stations, pp 13

Percival, Annthea; Benn, Dina K.; Simmons, Denise A.

Application of Geospatial Methods to Support Water Quality Assessment in Guyana, pp 46

Persaud, Ajay A.; Simmons, Denise A.; Ketwaru, Patrick

A Study on the Effect of Temperature and Storage Time on the Leaching of Antimony (Sb) from Polyethylene Terephthalate Drinking Water Bottles, pp 32

Sawh, Natasha; Bynoe, Paulette; Simmons, Denise A.

An Environmental Audit of Aracari Resort, pp 18

Singh, Lakeram; Hamer, Seon; Liverpool, Elford

A Study on the Relationship between the Ité Palm (Mauritia flexuosa) and the Tapir

(Tapirus terrestris) at Pakuri, pp 50

Steele, Chamique C.; Liverpool, Elford; Singh, Lucina

An Experiment on the Behavioural, Morphometric, and Histopathological Effects of

Paraquat Dichloride on Nile Tilapia Fingerlings, pp 36

Tucker, Merissa; Mallampati, Tabitha

An Assessment of Healthcare Workers' exposure to Health Hazards in the Accident and

Emergency Unit at Georgetown Public Hospital Corporation, pp 33

Williams, Ronilcia; Ansari, Abdullah; Bullen, Courtney

Investigating the Use of Water Hyacinth and Rice Hull Biochars to Improve the Growth of Vigna unguiculata in Cadmium Contaminated Soils, pp 27

Wilson, Shania; Benn, Dina K.; Edinboro, Rawle

Environmental Problems at Government Housing Schemes: The Case of Five-Miles, Bartica, pp 19

Woodroffe, Stayon; Bullen, Courtney

Soil Characterisation Assessment of the Acacia mangium Plantation at Dakoura, Linden, pp 28 


\section{BOOK OF ABSTRACTS STUDENT RESEARCH}

\section{0}

\section{A compilation of the Department of Environmental Studies, Faculty of Earth and Environmental Sciences}

The Book of Abstracts Student Research 2020 is a collection of student undergraduate research emerging from the Department of Environmental Studies at the Faculty of Earth and Environmental Studies, University of Guyana. This first volume comprises topics covering climate change, air and water quality, ethno-meteorology, and wildlife ecology; and demonstrates the quality and diversity of research pursued by our students. It is our hope that this book will enhance interest in the respective subject areas, and that the findings are applied to inform development in Guyana.

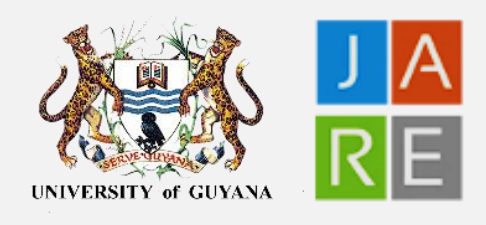

Journal of Academic Research and Essays (JARE)

Faculty of Earth and Environmental Sciences

Leslie P. Cummings Building

University of Guyana - Turkeyen Campus

Turkeyen, Greater Georgetown

Guyana

P.O. Box 10-1110 